\title{
molecules
}

ISSN 1420-3049

Article

www.mdpi.com/journal/molecules

\section{A New Phenolic Glycoside from the Barks of Cinnamomum cassia}

\section{Junfen Zeng ${ }^{2,3, \dagger}$, Yongbo Xue ${ }^{3, \dagger}$, Yongji Lai ${ }^{3}$, Guangmin Yao ${ }^{3}$, Zengwei Luo ${ }^{3}$, Yonghui Zhang ${ }^{3}$ and Jinwen Zhang ${ }^{1, *}$}

1 Tongji Hospital Affiliated to Tongji Medical College, Huazhong University of Science and Technology, Wuhan 430030, China

2 Department of Pharmacy, Renmin Hospital of Wuhan University, Wuhan 430060, China

3 Hubei Key Laboratory of Natural Medicinal Chemistry and Resource Evaluation, School of Pharmacy, Tongji Medical College, Huazhong University of Science and Technology, Wuhan 430030, China

$\dagger$ These authors contributed equally to this work.

* Author to whom correspondence should be addressed; E-Mail: tjzhangjinwen@163.com; Tel.: +86-27-8366-3253; Fax: +86-27-8369-2762.

External Editor: Derek J. McPhee

Received: 25 September 2014; in revised form: 29 October 2014 / Accepted: 29 October 2014 / Published: 31 October 2014

\begin{abstract}
A new phenolic glycoside (1), named methyl 2-phenylpropanoate-2- $O-\beta$-Dapiofuranosyl-( $1 \rightarrow 6)-O-\beta$-D-glucopyranoside, was isolated from the barks of Cinnamomum cassia, along with three known phenolic glycosides and four known lignan glycosides. The structure of $\mathbf{1}$ was elucidated by extensive interpretation of spectroscopic data and chemical method. Selected compounds were evaluated for their immunosuppressive activities against murine lymphocytes. Compounds 1, 2, 6 and 8 exhibited differential inhibition against ConA-induced T cells proliferation.
\end{abstract}

Keywords: Cinnamomum cassia; phenolic glycoside; immunosuppressive activities

\section{Introduction}

The plant Cinnamomum cassia (Lauraceae), which originates in the south of China, is widely cultivated in tropical or subtropical areas, such as Fujian, Guangdong, Guangxi, Yunnan and Hainan 
Provinces of China, as well as Taiwan, India, Indonesia, Laos, Malysia, Thailand and Vietnam [1]. The bark of $C$. cassia, well known as Cinnamomi cortex in China, has long been used as spice and flavoring agents [2]. It also possesses various biological activities, such as insecticidal, anti-allergy, antipyretic, anticancer, anti-Alzheimer's disease, antidiabetic [3] and immunosuppressive activity [4]. In our previous study [5], three diterpenoids, cinncassiols $\mathrm{F}$ and $\mathrm{G}$, and 16-O- $\beta$-D-glucopyranosyl-19deoxycinncassiol $\mathrm{G}$, with unprecedented carbon skeletons, were isolated from the barks of $C$. cassia. It is notable that two of them showed significant inhibitory effects on the proliferation of murine $\mathrm{T}$ cells induced by ConA. Recently, with the aim of discovering more bioactive compounds from C. cassia, the extracts of EtOAc and $n-\mathrm{BuOH}$ were further phytochemically studied, which led to the isolation of a new phenolic glycoside (1), together with three known phenolic glycosides (2-4) and four known lignan glycosides (5-8). The immunomodulatory activities against murine lymphocytes of the selected compounds were reported in this work.

\section{Results and Discussion}

The EtOAc extract of $C$. cassia was separated by various chromatographic techniques to yield a new phenolic glycoside (1), along with seven known compounds. The known compounds were identified as 3,4,5-trimethoxyphenol- $\beta$-D-apiofuranosyl-( $1 \rightarrow 6)-O$ - $\beta$-D-glucopyranoside (2) [6],

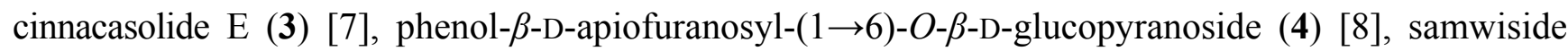
(5) $[9], \quad(6 R, 7 R, 8 R)-7 \mathrm{a}-[(\beta$-D-glucopyranosyl)oxy $]$ lyoniresinol $\quad(6) \quad[10], \quad(6 S, 7 R, 8 R)-7 \mathrm{a}-[(\beta$-Dglucopryanosyl)oxy]lyoniresinol (7) [10], and (6R,7S,8S)-7a-[( $\beta$-D-glucopyranosyl)oxy]lyoniresinol (8) [11], by comparison of their NMR data with those reported in literatures (Figure 1).

Figure 1. Structures of 1-8.

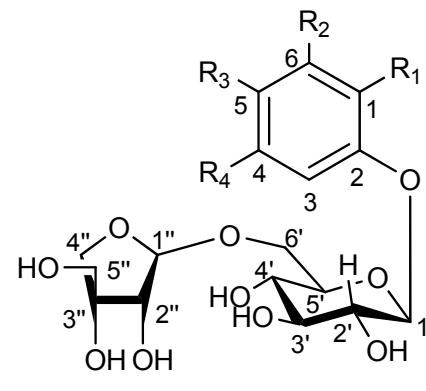

$$
\begin{aligned}
1 R_{1} & =R_{2}=R_{3}=R_{4}=H \\
2 R_{1} & =H, R_{2}=R_{3}=R_{4}=O_{3} H_{3} \\
3 R_{1} & =R_{3}=O \mathrm{OCH}_{3}, R_{2}=R_{4}=H \\
4 R_{1} & =R_{2}=R_{3}=R_{4}=H
\end{aligned}
$$<smiles>COC[C@H]1Cc2cc(OC)c(O)c(O)c2[C@H](c2cc(OC)c(O)c(OC)c2)C1CO</smiles>

$66 R, 7 S, 8 S$

$76 R, 7 R, 8 R$

$86 S, 7 R, 8 S$

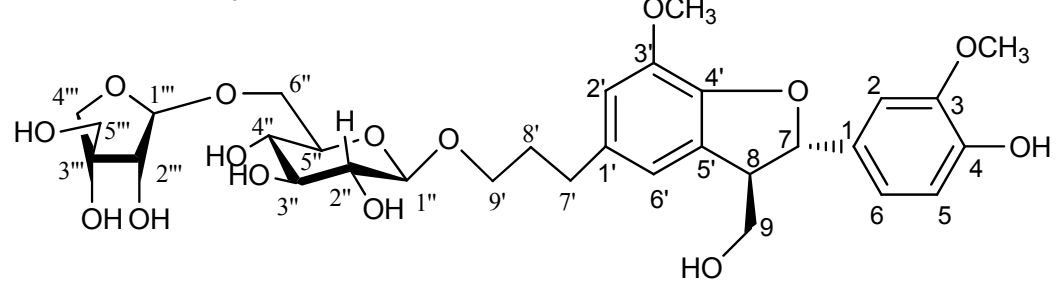


Compound 1 was isolated as amorphous powder, with $[\alpha]_{\mathrm{D}}^{25}-65.1(c=0.47, \mathrm{MeOH})$. Its molecular formula, $\mathrm{C}_{21} \mathrm{H}_{30} \mathrm{O}_{12}$, was deduced from the HRESIMS peak at $\mathrm{m} / z 497.1616[\mathrm{M}+\mathrm{Na}]^{+}$(calcd for $\left.\mathrm{C}_{21} \mathrm{H}_{30} \mathrm{O}_{12} \mathrm{Na}, 497.1629\right)$. The IR spectrum showed the presence of carbonyl $\left(1719 \mathrm{~cm}^{-1}\right)$ and hydroxyl group (3391 $\left.\mathrm{cm}^{-1}\right)$. The ${ }^{1} \mathrm{H}$ NMR spectrum of $\mathbf{1}$ (Table 1) showed proton signals for a 1,2-disubstituted aromatic ring $\left(\delta_{\mathrm{H}} 7.21, \mathrm{dd}, J=8.1,1.2 \mathrm{~Hz}, \mathrm{H}-3 ; 7.18\right.$, ddd, $J=8.1,7.9,1.9 \mathrm{~Hz}, \mathrm{H}-4$; 6.96, ddd, $J=7.9,7.9,1.2 \mathrm{~Hz}, \mathrm{H}-5$; and 7.17, dd, $J=7.9,1.9 \mathrm{~Hz}, \mathrm{H}-6)$, a methoxyl ( $\left.\delta_{\mathrm{H}} 3.66, \mathrm{~s}\right)$. ${ }^{13} \mathrm{C}-\mathrm{NMR}$ and DEPT spectra (Table 1) of 1 showed 21 carbon signals, including one methoxyl, one ester carbonyl, five methylenes, eleven methines, and three quaternary carbons. Comparison of the ${ }^{1} \mathrm{H}$ - and ${ }^{13} \mathrm{C}$-NMR spectra with those of $\mathbf{4}$ revealed that $\mathbf{1}$ differed from $\mathbf{4}$ by the presence of a methyl propionate at $\mathrm{C}-1$. Thus, compound 1 was determined to be an analogue of 4 . The HBMC and ${ }^{1} \mathrm{H}-{ }^{1} \mathrm{H}$ COSY spectra of 1 indicated the presence of a methyl propionate moiety, which was connected at $\mathrm{C}-1$.

The HBMC correlations from $\mathrm{H}-1^{\prime}$ to $\mathrm{C}-2$ and from $\mathrm{H}-1^{\prime \prime}$ to $\mathrm{C}-6^{\prime}$ revealed the linkages of the two sugars to be the same as those of 4 . The sugars were finally confirmed by comparing the retention times of the three trimethylsilylthiazolidine derivatives obtained from GC analysis. On the basis of the above evidences, compound $\mathbf{1}$ was determined and named methyl 2-phenylpropanoate-2-O- $\beta$-Dapiofuranosyl-( $1 \rightarrow 6)-O-\beta$-D-glucopyranoside.

Table 1. ${ }^{1} \mathrm{H}-(400 \mathrm{MHz})$ and ${ }^{13} \mathrm{C}-\mathrm{NMR}(100 \mathrm{MHz})$ Data of $\mathbf{1}$ in $\mathrm{CD}_{3} \mathrm{OD}$.

\begin{tabular}{ccc}
\hline Position & $\boldsymbol{\delta}_{\mathbf{H}}$ & $\boldsymbol{\delta}_{\mathbf{C}}$ \\
\hline 1 & & 131.3 \\
2 & & 157.0 \\
3 & $7.21 \mathrm{dd}(8.1,1.2)$ & 128.9 \\
4 & $7.18 \mathrm{ddd}(8.1,7.9,1.9)$ & 116.7 \\
5 & $6.96 \mathrm{ddd}(7.9,7.9,1.2)$ & 123.5 \\
6 & $7.17 \mathrm{dd}(7.9,1.9)$ & 131.0 \\
7 & $3.00 \mathrm{~m}$ & 26.9 \\
8 & $2.68 \mathrm{t}(7.7)$ & 35.3 \\
9 & & 175.9 \\
OMe & $3.66 \mathrm{~s}$ & 52.0 \\
$1^{\prime}$ & $4.88 \mathrm{~d}(7.8)$ & 102.8 \\
$2^{\prime}$ & $3.50 \mathrm{~m}$ & 75.0 \\
$3^{\prime}$ & $3.49 \mathrm{~m}$ & 78.2 \\
$4^{\prime}$ & $3.38 \mathrm{~m}$ & 71.6 \\
$5^{\prime}$ & $3.60 \mathrm{~m}$ & 77.0 \\
$6^{\prime} \mathrm{a}$ & $4.04 \mathrm{~d}(10.6)$ & 68.8 \\
$6^{\prime} \mathrm{b}$ & $3.64 \mathrm{~m}$ & \\
$1^{\prime \prime}$ & $5.00 \mathrm{~d}(2.3)$ & 111.0 \\
$2^{\prime \prime}$ & $3.93 \mathrm{~d}(2.3)$ & 78.1 \\
$3^{\prime \prime}$ & & 80.0 \\
$4^{\prime \prime} \mathrm{a}$ & $3.77 \mathrm{~d}(9.7)$ & 75.0 \\
$4^{\prime \prime} \mathrm{b}$ & $3.97 \mathrm{~d}(9.7)$ & \\
$5^{\prime \prime}$ & $3.61 \mathrm{~s}$ & 65.6 \\
\hline & &
\end{tabular}


The crude extract of $C$. cassia has been reported to exhibit potent anti-complement [12] and immunosuppressive activities [4]. Thus, compounds 1, 2, and 5-8 were evaluated for their immunomodulatory activities against murine lymphocytes. The results (Table 2) showed that compounds 1, 2, 6, and 8 inhibited the proliferation of ConA-induced murine $T$ cells at a concentration of $50 \mu \mathrm{M}$, while the positive control at the concentration of $50 \mu \mathrm{M}$, resulted in an inhibitory ratio of $106.1 \%$ against $\mathrm{T}$ cells and an inhibitory ratio of $75.8 \%$ against $\mathrm{B}$ cells.

Table 2. Effects on Murine Lymphocyte Proliferation Induced by Concanavalin A (ConA) $(5 \mu \mathrm{g} / \mathrm{mL})$ or Lipopolysaccharide (LPS) $(10 \mu \mathrm{g} / \mathrm{mL})$ of the Selected Compounds 1, 2, and $5-\mathbf{8}^{a}$.

\begin{tabular}{|c|c|c|c|}
\hline \multirow{2}{*}{ Compounds } & \multirow{2}{*}{$\begin{array}{c}\text { Concentration } \\
(\mu \mathrm{M})\end{array}$} & \multicolumn{2}{|c|}{${\text { Inhibitory/Enhanced Rate }(\%)^{b}}^{b}$} \\
\hline & & ConA-Induced T Cell Proliferation & LPS-Induced B Cell Proliferation \\
\hline \multirow{5}{*}{1} & 200 & -56.7 & 10.3 \\
\hline & 100 & -61.2 & $\mathrm{c} 25.2$ \\
\hline & 50 & -35.4 & 25.6 \\
\hline & 25 & -22.1 & 30.1 \\
\hline & 12.5 & 15.2 & 7.8 \\
\hline \multirow{5}{*}{2} & 200 & -45.2 & -35.1 \\
\hline & 100 & -38.8 & -5.8 \\
\hline & 50 & -8.5 & -12.5 \\
\hline & 25 & -12.5 & 10.3 \\
\hline & 12.5 & -20.1 & 6.2 \\
\hline \multirow{5}{*}{5} & 200 & -27.9 & 28.4 \\
\hline & 100 & -5.4 & 22.2 \\
\hline & 50 & 6.5 & 10.7 \\
\hline & 25 & 11.7 & -1.5 \\
\hline & 12.5 & 2.8 & 13.8 \\
\hline \multirow{5}{*}{6} & 200 & -47.7 & -13.2 \\
\hline & 100 & -58.0 & 20.5 \\
\hline & 50 & -23.6 & 41.4 \\
\hline & 25 & -47.5 & 36.1 \\
\hline & 12.5 & -11.3 & -12.5 \\
\hline \multirow{5}{*}{7} & 200 & -10.4 & -22.7 \\
\hline & 100 & -13.8 & 78.5 \\
\hline & 50 & 2.5 & 62.4 \\
\hline & 25 & 18.7 & 58.4 \\
\hline & 12.5 & 35.1 & 12.5 \\
\hline \multirow{5}{*}{8} & 200 & $-80.1 *$ & -46.7 \\
\hline & 100 & -58.3 & -10.3 \\
\hline & 50 & -19.5 & 25.6 \\
\hline & 25 & 27.8 & 57.8 \\
\hline & 12.5 & 14.5 & 52.2 \\
\hline \multirow{5}{*}{ CsA } & 200 & $-109.8 * *$ & $-106.1 * *$ \\
\hline & 100 & $-106.0 * *$ & $-94.8 * *$ \\
\hline & 50 & $-106.1 * *$ & $-75.8 *$ \\
\hline & 25 & $-97.1 * *$ & -60.1 \\
\hline & 12.5 & $-84.5 * *$ & -54.5 \\
\hline
\end{tabular}

${ }^{a}$ Results are represented as mean \pm SD based on three independent experiments. ${ }^{b}$-Inhibitory effect; + stimulatory effect. $(n=3 ; * p<0.05 ; * * p<0.01$ compared with control). Positive control: ConA or LPS; negative control: DMSO. 


\section{Experimental}

\subsection{General Procedures}

NMR spectra were recorded on a Bruker AM 400 spectrometer (Bruker, Ettlingen, Germany), and

the ${ }^{1} \mathrm{H}$ - and ${ }^{13} \mathrm{C}$-NMR chemical shifts were referenced to the solvent peaks for $\mathrm{CD}_{3} \mathrm{OD}$ at $\delta_{\mathrm{H}} 3.31$ and $\delta_{C}$ 49.15. HRESI-MS data were measured on a LC-LTQ-Orbitrap XL spectrometer (Thermo Fisher, Waltham, MA, USA). Optical rotations were determined on a Perkin-Elmer PE-341LC polarimeter (PerkinElmer, Waltham, MA, USA). IR spectra were recorded on a Bruker VERTEX 70 spectrometer (Bruker, Ettlingcn, Germany). UV spectra were recorded on a PerkinElmer Lambda 35 spectrophotometer (PerkinElmer, Waltham, MA, USA). Semi-preparative HPLC was performed on an Agilent 1100 liquid chromatography (Agilent, Santa Clara, CA, USA) with an YMC $(10 \times 250 \mathrm{~mm}, 5 \mu \mathrm{m})$ column. GC analysis was performed with a capillary column $(30 \mathrm{~m} \times 0.32 \mathrm{~mm} \times 0.5 \mu \mathrm{m})$ on an Agilent 7890A GC. Silica gel (200-300 mesh, Qingdao Marine Chemical Inc., Qingdao, China), ODS (50 $\mu$ m, YMC, Kyoto, Japan), and Sephadex LH-20 (Pharmacia Biotech AB, Stockholm, Sweden) were used for column chromatography.

\subsection{Plant Material}

The barks of $C$. cassia were collected at Qujing, Yunan Province, China, in July 2010. The plant material was identified by Prof. Changgong Zhang at the School of Pharmacy, Tongji Medical College, Huazhong University of Science and Technology. A voucher specimen (No. 2010-0703) was deposited in the herbarium of Hubei Key Laboratory of Natural Medicinal Chemistry and Resource Evaluation, Tongji Medical College, Huazhong University of Science and Technology.

\subsection{Extraction and Isolation}

The air-dried stem barks of C. cassia $(25 \mathrm{~kg})$ were extracted with $95 \%$ ethanol at room temperature three times. The EtOH extract was concentrated in vacuo $(2.6 \mathrm{~kg})$, and then suspended in water and partitioned successively with petroleum ether, $\mathrm{CHCl}_{3}$, EtOAc, and $n$ - $\mathrm{BuOH}$. The EtOAc soluble extract was subjected to column chromatography (CC) (100-200 mesh) over silica gel, eluting with a gradient of $\mathrm{CHCl}_{3} / \mathrm{MeOH}$ to yield fractions 1-6. Fraction 3 (16 g) was chromatographed on YMC gel column (ODS) eluted with $\mathrm{MeOH} / \mathrm{H}_{2} \mathrm{O}(10 \%-70 \%)$, and on silica gel with a gradient of $\mathrm{CHCl}_{3} / \mathrm{MeOH}$ (from 25:1 to 10:1) to afford compounds 2 (25 mg), 3 (18 mg), and 4 (20 mg). Compound 1 (15 mg) was isolated from fraction 4 and purified by semipreparative $\mathrm{HPLC}\left(\mathrm{MeOH} / \mathrm{H}_{2} \mathrm{O}, 30: 70\right)$. Fraction 5 (21 g) was chromatographed on a silica gel $\mathrm{CC}$ with a gradient of $\mathrm{CHCl}_{3} / \mathrm{MeOH}(15: 1)$ to yield two subfractions 5.1 and 5.2. Compound $5(15 \mathrm{mg})$ was purified from fraction 5.1 by semipreparative HPLC $\left(\mathrm{MeOH} / \mathrm{H}_{2} \mathrm{O}, 20: 80\right)$, compounds $6(8 \mathrm{mg}), 7(5 \mathrm{mg})$, and $\mathbf{8}(10 \mathrm{mg})$ were isolated from fraction 5.2.

\subsection{Acid Hydrolysis}

A solution of $1(2.0 \mathrm{mg})$, in $2 \mathrm{M}$ aqueous $\mathrm{CF}_{3} \mathrm{COOH}(2.0 \mathrm{~mL})$ was heated at $60{ }^{\circ} \mathrm{C}$ for $2 \mathrm{~h}$ in a water bath [13]. The reaction mixture was diluted in $\mathrm{H}_{2} \mathrm{O}(2.0 \mathrm{~mL})$ and extracted with EtOAc $(2.0 \mathrm{~mL} \times 3)$, then the aqueous layer was concentrated to remove $\mathrm{CF}_{3} \mathrm{COOH}$. The residue was 
dissolved in pyridine $(1.0 \mathrm{~mL})$, to which L-cysteine methyl ester hydrochloride $(2.0 \mathrm{mg})$ in pyridine $(1.0 \mathrm{~mL})$ was added. Then, the mixture was kept at $60{ }^{\circ} \mathrm{C}$ for $30 \mathrm{~min}$. After the reaction mixture was dried in vacuo, the residue was trimethylsilylated with 1-trimethylsilylimidazole $(0.4 \mathrm{~mL})$ at $60{ }^{\circ} \mathrm{C}$ for $30 \mathrm{~min}$ in a water bath. Finally, the mixture was partitioned between $n$-hexane and $\mathrm{H}_{2} \mathrm{O}(1 \mathrm{~mL}$ each) and the $n$-hexane extract was analyzed by gas chromatography (GC) under the following conditions: column temperature, $250{ }^{\circ} \mathrm{C}$; injection temperature, $250{ }^{\circ} \mathrm{C}$; carrier $\mathrm{N}_{2}$ gas; flow rate $1.0 \mathrm{~mL} / \mathrm{min}$. In the acid hydrolysate of 1 , D-glucose and D-apiose were confirmed by comparison of the retention times of their derivatives with those of D-glucose and D-apiose derivatives prepared in a similar way, which showed retention times of 10.03 and $15.62 \mathrm{~min}$.

Methyl 2-phenylpropanoate-2-O- $\beta$-D-apiofuranosyl-( $1 \rightarrow 6)-O-\beta$-D-glucopyranoside (1): amorphous powder; $[\alpha]_{\mathrm{D}}^{25}-65.1(c=0.47, \mathrm{MeOH})$; UV (MeOH) $\lambda_{\max }(\log \varepsilon)=213(2.9) \mathrm{nm}$; IR $(\mathrm{KBr}) v_{\max } 3391$, 2926, 2884, 1719, 1493, 1236, 1067, and $756 \mathrm{~cm}^{-1}$; ${ }^{1} \mathrm{H}-\mathrm{NMR}\left(\mathrm{CD}_{3} \mathrm{OD}, 400 \mathrm{MHz}\right)$ and ${ }^{13} \mathrm{C}-\mathrm{NMR}(\mathrm{CD} 3 \mathrm{OD}$, $100 \mathrm{MHz}$ ) see Table 1; HRESIMS $m / z$ : $497.1616[\mathrm{M}+\mathrm{Na}]^{+}$(calcd for $\mathrm{C}_{21} \mathrm{H}_{30} \mathrm{O}_{12} \mathrm{Na}, 497.1629$ ).

\subsection{Lymphocyte Proliferation Test}

Splenic lymphocytes were prepared as previously described by Kawaguchi et al. [14]. The lymphocyte proliferation was determined by WST-8 assay using Cell Counting Kit-8 (Dojindo) [15]. The prepared spleen cells $\left(2.5 \times 10^{6}\right.$ cells $)$ were seeded into each well of a 96-well microplate, and various concentrations of compounds and $5 \mu \mathrm{g} / \mathrm{mL}$ of concanavalin A (Con A, from Canavaliaensiformis Type III), for selective stimuli on T cells were added, cyclosporine A (CsA) was used as a positive control. After being cultured at $37{ }^{\circ} \mathrm{C}$ with $5 \% \mathrm{CO}_{2}$ for $48 \mathrm{~h}, 20 \mu \mathrm{L}$ WST- 8 was added to each well. The absorbance at $450 \mathrm{~nm}$ with a $600 \mathrm{~nm}$ reference was detected on a microtiter plate reader (Bio-Rad 680). All optical density (OD) values shown are the mean of triplicate sample \pm SD. Controls with and without ConA and LPS were used to establish the baseline proliferation for stimulated and unstimulated cells. The lymphocyte proliferation rate was evaluated according to our reported procedure [5].

\section{Conclusions}

A new phenolic glycoside, methyl 2-phenylpropanoate-2- $O-\beta$-D-apiofuranosyl- $(1 \rightarrow 6)-O-\beta$-Dglucopyranoside (1), was isolated from the barks of $C$. cassia, together with seven known compounds (2-8). The structure and relative configuration of the new isolate was elucidated by careful interpretation of spectroscopic data. This is the first report of samwiside (5) in the genus of Cinnamomum. Compounds 1, $\mathbf{2}$ and 5-8 were tested for their in vitro immunomodulatory activities. Compounds $\mathbf{2}$ and 6 showed weak inhibition against ConA-induced $\mathrm{T}$ cell proliferation at the dosage of $12.5-200 \mu \mathrm{M}$, and the inhibitory effects are not dose-dependent. Interestingly, at a concentration of $200 \mu \mathrm{M}$, compound 8 significantly inhibited ConA-induced $\mathrm{T}$ cell proliferation with an inhibition ratio of $80.1 \%$, whilst at low concentrations of 25 and $12.5 \mu \mathrm{M}$, stimulated the proliferation of $\mathrm{T}$ cell.

\section{Acknowledgments}

We are grateful to Changgong Zhang at Huazhong University of Science and Technology for the authentication of this plant material. This project was financially supported by the National Natural 
Science Foundation of China (31370372, 81202423, and 31200258), Program for New Century Excellent Talents in University, State Education Ministry of China (NCET-2008-0224).

\section{Author Contributions}

Jinwen Zhang and Yonghui Zhang designed the research; Junfen Zeng, Yongji Lai, Yongbo Xue, Guangmin Yao, and Zengwei Luo performed research and analyzed the data; Jinwen Zhang and Yonghui Zhang wrote the paper. All authors read and approved the final manuscript.

\section{Conflicts of Interest}

The authors declare no conflict of interest.

\section{References}

1. Flora of China Editorial Committee. Flora of China; Science Press: Beijing, China; Missouri Botanical Garden Press: St. Louis, MO, USA, 2008; Volume 7, p. 102.

2. Choi, J.; Lee, K.T.; Ka, H.; Jung, W.T.; Jung, H.J.; Park, H.J. Constituents of the essential oil of the Cinnamomum cassia stem bark and the biological properties. Arch. Pharm. Res. 2001, 24, 418-423.

3. Chinese Pharmacopoeia Commission. Chinese Pharmacopoeia, 2010 ed.; Chemical Industry Press: Beijing, China, 2010; Part I, p. 128.

4. Zeng, X.Y.; Chen, X.F.; Wei, B.W. Study on immunosuppressive activity of Cinnamomum cassia extract. Guangxi Yixue 1984, 6, 62-64.

5. Zeng, J.F.; Xue, Y.B.; Shu, P.H.; Qian, H.Q.; Sa, R.J.; Xiang, M.; Li, X.N.; Luo, Z.W.; Yao, G.M.; Zhang, Y.H. Diterpenoids with Immunosuppressive Activities from Cinnamomum cassia. J. Nat. Prod. 2014, 77, 1948-1954.

6. Tran, M.N.; Nguyen, M.K.; Do, T.H.; Nguyen, X.N.; Bui, H.T.; Dao, V.D.; Hoang, L.; Doan, C.S.; KiHwan, B. Xanthine oxidase inhibitory activity of constituents of Cinnamomum cassia twigs. Bioorg. Med. Chem. Lett. 2012, 22, 4625-4628.

7. Sunghwa, F.; Koketsu, M. Phenolic and bis-iridoid glycosides from Strychnos cocculoides. Nat. Prod. Res. 2009, 23, 1408-1415.

8. Watanabe, S.; Hashimoto, I.; Hayashi, K.; Yagi, K.; Asai, T.; Knapp, H.; Straubinger, M.; Winterhalter, P.; Watanabe, N. Isolation and identification of 2-phenylethyl disaccharide glycosides and mono glycosides from rose flowers, and their potential role in scent formation. Biotechnol. Biochem. 2001, 65, 442-445.

9. Xiao, H.H.; Dai, Y.; Wong, M.S.; Yao, X.S. New lignans from the bioactive fraction of Sambucus williamsii Hance and proliferation activities on osteoblastic-like UMR106 cells, Fitoterapia 2014, 94, 29-35.

10. Yang, Y.L.; Chang, F.R.; Wu, Y.C. Squadinorlignoside: A novel 7, 9'-dinorlignan from the stems of Annona squamosal. Helv. Chim. Acta 2005, 88, 2731-2737.

11. Nie, T.T.; Zhao, H.X.; Bai, H. Chemical constituents of Pittosporum glabratum. Chin. J. Nat. Prod. 2011, 9, 180-184. 
12. Yagi, A.; Tokubuchi, N.; Nohara, T.; Nonaka, G.; Nishioka, I.; Koda, A. The constituents of cinnamomi cortex. I. structures of cinncassiol A and its glucoside. Chem. Pharm. Bull. 1980, 28, 1432-1436.

13. Lin, H.C.; Lee, S.S. Dibenzocycloheptanoids from the leaves of Cinnamomum subavenium. J. Nat. Prod. 2012, 75, 1735-1743.

14. Kawaguchi, T.; Matsumoto, I.; Osawa, T.J. Studies on hemagglutinins from Maackia amurensis seeds. Biol. Chem. 1974, 249, 2786-2792.

15. Yamamoto, Y.; Mochida, J.; Sakai, D.; Nakai, T.; Nishimura, K.; Kawada, H.; Hotta, T. Upregulation of the viability of nucleus pulposus cells by bone marrow-derived stromal cells: Significance of direct cell-to-cell contact in coculture system. Spine 2004, 29, 1508-1514.

Sample Availability: Samples of the compounds 1-8 are available from the authors.

(C) 2014 by the authors; licensee MDPI, Basel, Switzerland. This article is an open access article distributed under the terms and conditions of the Creative Commons Attribution license (http://creativecommons.org/licenses/by/4.0/). 